\title{
DECISION MODEL BASED ON ANALYTICAL HIERARCHY PROCESS FOR MANAGING THE ENVIRONMENTAL RISKS WITHIN THE ENVIRONMENTAL MANAGEMENT SYSTEMS
}

\author{
G.M. Arama, L.F.Pascu, D.Guta \\ INCD-ECOIND Bucharest Drumul Podu Dambovitei 71-73, Sect. 6, Zip Code \\ 060652; email:madalinaarama@yahoo.com; evmt@incdecoind.ro; \\ ecoind@incdecoind.ro; Romania
}

\begin{abstract}
The environmental protection issue at the national level and within organizations is very complex, due to a multitude of involved factors. To take the most appropriate decisions in normal/critical situations, a series of methods of analysis have been elaborated and implemented. The work presents the Analytical Hierarchy Process - English acronym AHP - as a multi-criteria decision instrument for modeling the preferences representations. This methodological instrument, special dedicated for environmental group decision in the field of environment, is a useful one in the process of decision taking, making it less prone to the subjectivity of value judgments by using a set of prior consensual agreed relevant criteria. The proposed decision model helps decision-makers to highlight the hazards of different planned and unplanned pollutants discharges and to assess the possible environmental risk due to the significant pollution evolution in the context of organization site conditions.
\end{abstract}

Keywords: $A H P$, environmental risk

\section{Introduction}

The paper aim is to present a qualitative risk assessment methodology for the use at the organizational level to support organization management measures in order to prevent the irreversible environmental degradation [1]. It is based on Analytical Hierarchy Process (English acronym AHP), a multi criteria decision instrument for modelling the preferences representations. This type of methodological instrument, special dedicated for group decision, makes the decision process less prone to the subjectivity of evaluators' value judgements by using a set of consensual, prior agreed relevant criteria. The paper discusses how this decision method can be used within organization.

\section{Materials and Methods}

To decide means to have information, knowledge and experience about a topic and a set of criteria to analyze the available evidences. This way, an informed decision can be achieved in due time [2]. Usually each person can set its own 
hierarchy of the chosen criteria according to their importance in its own view and distributes the available evidences for the decision topic to each ranked criteria according to his/her preference based on his/her knowledge and experience. If this type of behavior is put into a reasoning scheme structure then, one can obtain what is usually called a multicriteria instrument for taking informed and reproducible decision. Within this reasoning scheme, first decision objectives should be analyzed. When a decision maker should take a decision he/she should respond to the question "what are the objectives to be accomplished?" Then a set of relevant criteria should be set based on which, the decision maker will choose one course of action or another knowing that each choice (alternative) has its own advantages/benefits and disadvantage/drawbacks [3]. At the organization level, anthropogenic actions can induce significant environmental impacts in the surrounding organization environment and according to the national and international law an environmental risk assessment may be required in order to assess the probability and the magnitude of pollution consequences. During periodic management analysis, the AHP methodological instrument can be a useful one, because it can help select the most efficient management alternatives able to mitigate the produced significant environmental impacts and eliminate and reduce their induced environmental risks. It can integrate information and experience from the entire organization, showing the relation between environmental policy objectives, primary criteria, sub-criteria and proposed available alternatives to fulfill those objectives making pair-wise comparisons among them [4]. In this paper for the sake of introducing this type of methodological instrument a following example will be given. Suppose that within an organization there are three plants named $R_{1}, R_{2}$ and $R_{3}$ that should be analyzed for their produced environmental significant impacts and possible environmental risks. Suppose that " $m$ " $(m=3)$ alternatives/environmental risk scenarios $R_{1}, . ., R_{m}$, have been proposed associated with the pollution brought in certain conditions by the three plants. Using AHP methodology they should be ranked in order to make appropriate mitigation measures. The alternatives/risk scenarios will be named $R_{1}, R_{2}$ and $R_{3}$. At the organization level, relevant environmental performance indicators records according with EMAS III [5] (English acronym for Environmental Management and Audit Scheme) and ISO 14031:2013 standard [6], are kept on regular basis. In this situation, we supposed that "n” $(n=3)$ decision criteria $C_{1, \ldots}, C_{n}$, can be chosen representing precisely those types of indicators namely ECI (English acronym for Environmental Performance Indicators), OPI (English acronym for Operational Performance Indicators) and MPI (English acronym for and Management Performance Indicators). They have been recommended to be used in any environmental management analysis for any organization having in place an EMS (English acronym for Environmental Management System) which is also the case of the presented organization. The criteria will be used to construct a hierarchy for assessing and ranking the alternatives/environmental risk scenarios having the objective presented in Table 1. 
Table 1. Hierarchical structure for environmental risk assessment

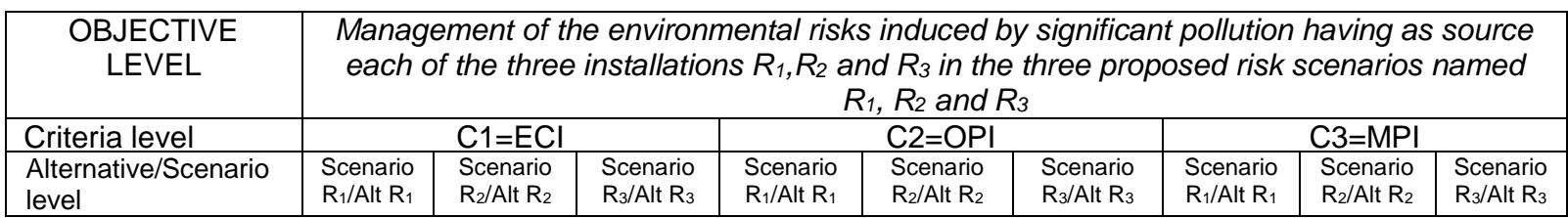

Using a scale given by Saaty who first presented this type of multicriteria methodology, a score for different lexical expressed judgments is given by each evaluator. Each evaluator should be able to express his/her preferences when comparing two criteria or alternatives/risk scenarios one relative to another. The score significance from the Saaty scale is presented next:

Score 1 - Equally important

Score 3 - Slightly "more important"

Score 5 - Moderate "more important"

Score 7 - A lot "more important"

Score 9 - Absolute "more important"

Score 2, 4, 6, 8 - Intermediate values - in-between two adjacent score values of this scale might be also used [7]. When in a pair wise comparison the relative importance of one object against the other is abolished then, the two objects equally contribute to the objective fulfillment (and this score is equal to 1). A practical example is given in Table 2. If two objects (either alternatives/risk scenarios or criteria) should be compared one to another then, the evaluator should express his/her preference for the most valuable/important one using the above-mentioned scale within a matrix named "pair wise comparison matrix" having rows and columns labeled with the compared objects. When the Alternative/Risk Scenario in the row is more important than the Alternative/Risk Scenario in the column considering criterion $C 1$ then the entry $\mathrm{P}_{A, C}$ in the matrix for example is greater than $1 \quad\left(p_{A, C}=2\right)$. If this is not the case (as in $p_{A, B}=1 / 3$ ) then, alternative/risk scenario in the row is less important than alternative/risk scenario from the column. A relevant simulated numerical example is presented next.

Table 2. Example of pair wise comparison matrix for alternative $R_{1}, R_{2}$ and $R_{3}$ and criterion 1

\begin{tabular}{|c|c|c|c|}
\hline Criterion C1 & $\begin{array}{l}\text { AlternativeR } \mathbf{1} / \text { Risk } \\
\text { scenarioR }\end{array}$ & $\begin{array}{l}\text { Alternative } \mathbf{R}_{\mathbf{2}} / \text { Risk } \\
\text { scenario } \mathbf{R}_{\mathbf{2}} \\
\end{array}$ & $\begin{array}{l}\text { Alternative } R_{3} / \text { Risk } \\
\text { scenario } R_{3}\end{array}$ \\
\hline $\begin{array}{c}\text { Alternative } \mathbf{R}_{1} / \\
\text { Risk scenario } \\
\mathbf{R}_{\mathbf{1}}\end{array}$ & $\begin{array}{l}p_{A, A}=1 \\
p_{A, A}=1.000 \text { (in decimal } \\
\text { format) }\end{array}$ & $\begin{array}{l}p_{A, B}=1 / 3 \\
p_{A, B}=0.333 \text { (in decimal } \\
\text { format) }\end{array}$ & $\begin{array}{l}p_{A, C}=2 \\
p_{A, C}=2.000 \text { (in decimal } \\
\text { format) }\end{array}$ \\
\hline $\begin{array}{c}\text { Alternative } \mathbf{R}_{\mathbf{2}} / \\
\text { Risk scenario } \\
\mathbf{R}_{\mathbf{2}}\end{array}$ & $\begin{array}{l}p_{B, A}=3 \\
p_{B, A}=3.000 \text { (in decimal } \\
\text { format) }\end{array}$ & $\begin{array}{l}p_{B, B}=1 \\
p_{B, B}=1.000 \text { (in decimal } \\
\text { format) }\end{array}$ & $\begin{array}{l}p_{B, C}=6 \\
p_{B, C}=6.000 \text { (in decimal } \\
\text { format) }\end{array}$ \\
\hline $\begin{array}{c}\text { Alternative } \mathbf{R}_{3} / \\
\text { Risk scenario } \\
\mathbf{R}_{\mathbf{3}}\end{array}$ & $\begin{array}{l}p_{C, A}=1 / 2 \\
p_{C, A}=0.500 \text { (in decimal } \\
\text { format) }\end{array}$ & $\begin{array}{l}p_{C, B}=1 / 6 \\
p_{C, B}=0.167 \text { (in decimal } \\
\text { format) }\end{array}$ & $\begin{array}{l}p_{C, C}=1 \\
p_{C, C}=1.000 \text { (in decimal } \\
\text { format) }\end{array}$ \\
\hline
\end{tabular}




\section{Results and Discussion}

We supposed that an organization having an implemented EMS wants to analyze its environmental performance indicators for the three installations. The purpose of this analysis using AHP is to characterize the environmental risk for the aquatic environment induced downstream on populated areas by the organization discharges. This is a very common encountered issue in a large majority of organizations around the globe [8]. Those three plants have similar output profile and accordingly similar pollutants' discharges. They discharge through the organization wastewater treatment plant that initially was designed to fit the organization necessities to reach the permit limits. However, in the last two years, changes in the output levels of those plants have been produced to respond to the increased market demands. They have been reorganized and technological improvements have been made but without adjustments for the environmental protection equipments. Consequently, the Maximum Allowable Concentration (English Acronym MAC) limits considered protective for the aquatic ecosystem have been exceeded on regular basis. In order to put in place supplementary protection barriers [9] to help eliminate those pollutants from its discharges, the organization wants to make some BAT type investments for environmental protection. In this respect, the organization invited at the yearly periodically EMS management analysis the main interested parties to form a panel to evaluate which installation of those three ones brings more pollution and is more risky for the local environment. The panel evaluators are: the environmental responsible persons from each installation $R_{1}, R_{2}$, and $R_{3}$, the organization environmental manager and a representative from the Local Environmental Agency. Each of the panel evaluators received records of values for $\mathrm{ECl}, \mathrm{OPI}$, and MPI type of indicators corresponding to the last year monitoring of the three plants. They should base their evaluations on the analysis of their intrinsic or relative values and trends. Next are given examples of such types of indicators used by the evaluators in order to apply this methodology which has been prior instructed in a short two-days instruction course They are of the same type for the three installations namely:

1. Example of ECl type indicators: The amount of specific pollutants discharged per year.

2. Example of OPI type indicators: Amount of existing adequate BAT treatment equipments /technologies in place and functional reported to the amount of necessary adequate BAT treatment equipments/technologies necessary

3. Example of MPI type indicators: Amount of money spent on fines in relation with the exceeding the permit values.

The evaluators were asked to rank the alternatives representing risk scenarios according to the available criteria C1, C2, and C3 type using each criteria at a time. The available given organization records and evaluators' knowledge and experience in the field will support the assessment of the proposed $R_{1}, R_{2}$, and $R_{3}$ scenarios. The assessment will give the necessary inputs to make appropriate environmental investments in order to mitigate or to 
reduce the induced environmental pollution risks. Their mature judgments will evaluate the premises for the amplification of pollution consequences for the downstream community in the next year supposing that the indicators will have approximately the same evolution as in the last year using AHP prior instructed methodology. They are required to fill in the pair wise comparisons matrices forms for criteria and alternatives/risk scenarios and their inputs will be automatically processed according to AHP [7]. A pair wise comparison matrix " $\mathrm{C}_{1,2,3-}-$ " for the C1, C2, and C3 criteria and the Evaluator I is given in Table 3 as an example of how the forms should be filled in. It expresses the preference given to each criterion by Evaluator I when considering their importance in their own view.

Table 3. Pair wise comparison matrix " $\mathrm{C}_{1,2,3-\mathrm{l}}$ " $(3 \times 3)$ in fractional format - an example

\begin{tabular}{|c|c|c|c|}
\hline Evaluator I & $\mathrm{C} 1$ & $\mathrm{C} 2$ & $\mathrm{C} 3$ \\
\hline $\mathrm{C} 1$ & 1 & 2 & 4 \\
$\mathrm{C} 2$ & $1 / 2$ & 1 & 3 \\
\hline $\mathrm{C} 3$ & $1 / 4$ & $1 / 3$ & 1 \\
\hline
\end{tabular}

The similar matrix is filled in by each evaluator for ranking criteria and alternative risk scenarios. Finally introducing the data in AHP automated algorithm, the three environmental risk scenarios have been ranked according to the evaluators given inputs. The obtained computed score allowed the following ranking: Alt $R_{3} /$ Risk Scenario $R_{3}$ first place, followed by Alt $R_{1} / R_{\text {isk }}$ Scenario $R_{1}$ in second place and Alt $R_{2} /$ Risk Scenario $R_{2}$ in third place.

To carry out this analysis the evaluators considered that: the environmental risk is a function of hazards, defined in this context as being the discharges into the aquatic ecosystem of one or more pollutants at concentrations greater than the permit or MAC limit. Worldwide, the endeavor to monitor and model the pollutants faith as well as to find adequately technologies for waste water to remove pollutants has as purpose to take adequate management measures for maintaining the good quality of the aquatic ecosystem water-body [12],[13],[14]. Evaluators have chosen the scenario $\mathrm{R}_{3}$ as increasing the premises of the amplification of pollution consequences in the given conditions followed by the scenarios $R_{1}$ and $R_{2}$ based on available given evidences in relation to the prior consensual agreed criteria. The obtained scores for the three risk scenarios are in good agreement with the proposed example constraints.

\section{Conclusions}

The proposed decision model helps decision-makers to highlight the pollution hazards and to assess the possible environmental risk in the context of organisation site conditions. It has the following advantages:

1) it can involve in a democratic manner the employees/stake-holders in decision making process as required by EMAS III and EMS ISO 14001:2005 standards;

2) it increases the organization accountability making the evaluation less prone to subjectivity by using prior agreed criteria. 
Implementation of it at the organizational level should be further developed being an appropriate instrument for putting in practice the latest environmental law and standards requirements.

\section{Acknowledgements}

Present paper has been developed under funding of Nucleu Program 13N/2009-PN 09-13.04.14/Ad. Act. 1/2015 and $2 / 2015$.

\section{References}

1. ZHANG, K., PEI Y., LIN, C., (2010), An Investigation of Correlation between Different Environmental Assessments and Risk Assessment, Procedia Environmental Sciences, 2, 643 - 649.

2. http://en.wikipedia.org/wiki/Decision-making

3. CHEN, Y., KILGOUR, D.M., HIPEL, K. W., (2008), Screening in Multiple Criteria Decision Analysis, Decision Support System, 45, 278 - 290.

4. ARUNRAJ, N.S, MAITI, J. (2010), Risk-based Maintenance Policy Selection Using AHP and Goal Programming, Safety Science, 48, 238 - 247.

5. EMAS III, (2009) Regulation (EC) No 1221 of the European Parliament and of the Council of 25 November 2009 on the voluntary participation by organizations in a Community Eco-Management and Audit Scheme (EMAS), repealing Regulation (EC) No 761/2001 and Commission Decisions 2001/681/EC and 2006/193/EC, Official Journal of the European Union 3421, pp. 1 - 45.

6. ISO 14031:2013 Environmental management - Environmental Performance evaluation - Guidelines.

7. SAATY, T.L., TRAN, L.T., (2007), On the Invalidity of Fuzzifying Numerical Judgments in the Analytic Hierarchy Process, Mathematical and Computer Modelling, 64, 962 - 975.

8. DOMINGUEZ-CHICAS, A., SCRIMSHAW, M.D., (2010), Hazard and risk assessment for indirect potable reuse schemes: An approach for use in developing Water Safety Plans, Water Research, 44, 6115 - 6123.

9. TIXIER, J., DANDRIEUX, A., DUSSERRE, G., BUBBICO, R., MAZZAROTTA, B., SILVETTI B., HUBERT, E. RODIGUES, N. SALVI O., (2006), Environmental Vulnerability Assessment in the Vicinity of an Industrial Site in the Frame of ARAMIS European project, Journal of Hazardous Materials, 130, 251 - 264.

10. TRIANTAPHYLLOU, E., (1995),Using the Analytic Hierarchy Process for Decision Making in Engineering Applications, Some Challenges, International Journal of Industrial Engineering: Applications and Practice, 2, (1), 35 - 44.

11. BOZÓKI, S., RAPCSÁK. T. (2008) On Saaty's and Koczkodaj's inconsistencies of pairwise comparison matrices, Journal of Global Optimization, 42 (2), 157-175.

12. BATRINESCU, G., BARSAN, E., VASILE, G. STANESCU B., STANESCU, E., PAUN, I. PETRESCU, FILOTE, M. C. (2011) Identification of the Aquatic Ecosystems Integrating Variables in the Suceava Hydrographic Basin and Their Correlations, Journal of Environmental Protection and Ecology, 12 (4),1627-1643.

13 BEKTESHI, A., MYRTAJ, E., (2014), Heavy metals in the Shkodra Lake Ecosystem, Journal of Environmental Protection and Ecology 15(3), 834 - 841.

14. MAMOUKARIS, A., MIMIS, S., KARAKOLIOS, E., XIPOLITOS, PATSIOURA, K., G., (2014), New Friendly to Environment Method in Wastewater Treatment, Journal of Environmental Protection and Ecology, 15 (3), 1021-1027. 